\title{
Growth hormone secretagogue receptor deficiency promotes lung cancer growth by affecting the Th17/Treg balance
}

\author{
Liang $\mathrm{Wu}^{1 *}$, Dongliang $\mathrm{Li}^{2 *}$, Linlin Qin ${ }^{3 \#}$, Qingliang Wang ${ }^{3}$, Yuichi Saito ${ }^{4}$, Ricciardi Sara ${ }^{5}$, Jiang Fan ${ }^{1}$ \\ ${ }^{1}$ Department of Thoracic Surgery, Shanghai First People's Hospital, Shanghai Jiao Tong University School of Medicine, Shanghai, China; \\ ${ }^{2}$ Department of Thoracic Surgery, Shanxi Provincial Tumor Hospital, Taiyuan, China; ${ }^{3}$ Department of Thoracic Surgery, Shanghai Pulmonary \\ Hospital, Tongji University School of Medicine, Shanghai, China; ${ }^{4}$ Department of Surgery, Teikyo University School of Medicine, Tokyo, Japan; \\ ${ }^{5}$ Division of Thoracic Surgery, IRCCS University Hospital of Bologna, Bologna, Italy \\ Contributions: (I) Conception and design: J Fan; (II) Administrative support: J Fan; (III) Provision of study materials or patients: All authors; (IV) \\ Collection and assembly of data: All authors; (V) Data analysis and interpretation: All authors; (VI) Manuscript writing: All authors. (VII) Final \\ approval of manuscript: All authors. \\ \#These authors contributed equally to this work. \\ Correspondence to: Jiang Fan. Department of Thoracic Surgery, Shanghai First People's Hospital, Shanghai Jiao Tong University School of Medicine, \\ Shanghai, China. Email: drjiangfan@yahoo.com.
}

Background: Cluster of differentiation $4\left(\mathrm{CD} 4^{+}\right) \mathrm{T}$ cells plays a prominent role in eliminating cancer cells. The balance between $\mathrm{T}$ helper (Th)17 and regulatory $\mathrm{T}$ (Treg) cells is crucial for optimal immune response and protection against cancer. Growth hormone secretagogue receptor 1a (GHSR1a), a member of the $G$ protein-coupled protein receptor superfamily, plays a critical role in immune cell function. The aim of our study is to investigate the role of GHSR1a in $\mathrm{CD}^{+} \mathrm{T}$ cell differentiation and lung cancer progression.

Methods: A subcutaneous lung cancer model was used to examine the role of GHSR1a in controlling tumor growth. Lewis lung carcinoma (LLC) cells were subcutaneously implanted into $G$ bsr $1 a^{-1-}$ mice and wild-type (WT) mice. The ratio of Th17 and Treg in the draining lymph node of $G b s r 1 a^{-/-}$mice and WT tumor-bearing mice was detected by fluorescence-activated cell sorting (FACS). The effect of GHSR1a deficiency on Th17 and Treg cell differentiation was examined using an in vitro differentiation assay. The phosphorylation of mammalian target of rapamycin (mTOR), signal transducer, and activator of transcription (STAT) 3 and STAT5 signaling was detected with Western blot.

Results: We found that the ablation of GHSR1a resulted in impaired anti-tumor immunity to control lung cancer growth in vivo. We also demonstrated that the deficiency of GHSR1a promoted a shift in the Th17/Treg balance toward enhanced Treg differentiation and inhibited Th17 differentiation both in vivo and in vitro, which suggests that GHSR1a regulates T cell lineage choices between Th17 and Treg cell commitment in the tumor microenvironment. Mechanistically, the deficiency of GHSR1a resulted in reduced phosphorylation in mTOR and STAT3, and increased phosphorylation in STAT5.

Conclusions: Our findings showed the important role of GHSR1a in CD4 ${ }^{+} \mathrm{T}$ cell differentiation in the context of the lung cancer microenvironment. This research provides a novel molecular target and insights into interventions for the prevention and treatment of lung cancer.

Keywords: Growth hormone secretagogue receptor 1a (GHSR1a); lung cancer; Th17/Treg balance; tumor immunity; microenvironment

Submitted Dec 22, 2020. Accepted for publication Nov 19, 2021.

doi: $10.21037 / \mathrm{atm}-21-5727$

View this article at: https://dx.doi.org/10.21037/atm-21-5727 


\section{Introduction}

Lung cancer has lengthily been considered a nonimmunogenic disease, however the immune response has recently recognized to have an important role in tumor development and progression (1). In addition to risk factors, such as smoking cigarettes, immune cells in the tumor microenvironment have also been identified as indispensable participants in lung cancer growth (2). Cluster of differentiation $4\left(\mathrm{CD}^{+}\right) \mathrm{T}$ cells are essential for optimal anti-tumor immunity. $\mathrm{CD}^{+} \mathrm{T}$ cells recognize tumor antigen presented by professional antigen-presenting cells (APC), support the activation and proliferation of $\mathrm{CD}^{+} \mathrm{T}$ cell and their differentiation into memory $\mathrm{CD} 8^{+}$ $\mathrm{T}$ cells and also regulate innate immunity in the tumor microenvironment $(3,4)$.

Research has shown the $\mathrm{T}$ helper (Th)17/regulatory $\mathrm{T}$ (Treg) cell axis is dysregulated in lung cancer $(5,6)$, which suggests that Th17/Treg balance may represent a promising target for lung cancer therapy. Notably, the relationship between Treg and Th17 cells appears to be close and highly complex. Both Treg and Th17 cells develop from the same precursor-naive $\mathrm{CD}^{+}{ }^{+} \mathrm{T}$ cells. The Th17 subtype is characterized by the production of cytokines IL-17A and IL-17F, and the differentiation of Th17 cells is dictated by the master transcription factor retinoidrelated orphan nuclear receptor $\gamma \mathrm{t}$ (ROR $\gamma \mathrm{t}$ ) (7). The Treg cells produce inhibitory cytokines, such as TGF- $\beta$, IL-10, and their differentiation is controlled by master regulator forkhead box P3 (Foxp3) cells. Pro-inflammatory cytokines, such as interleukin (IL)-6 and IL-23, could skew the balance toward Th17 differentiation over Treg development (8), while transforming growth factor- $\beta$ (TGF- $\beta$ ) and IL- 2 could induce the polarization of Treg (9). Recent studies suggest that energy metabolism also tunes the differentiation of Treg and Th17 cells. The mammalian target of rapamycin (mTOR) has emerged as an important regulator of the differentiation of Treg and Th17 cells (10). The inhibition of mTOR has been reported to expand Treg and inhibit the differentiation of Th17 cells.

Growth hormone secretagogue receptor 1a (GHSR1a), a member of the $G$ protein-coupled protein receptor superfamily, is the receptor for ghrelin, a 28 amino-acid peptide hormone, which was originally isolated from the stomach (11). GHSR1a is ubiquitously expressed in various tissues and cell types, including $\mathrm{T}$ cells (12). A number of studies have demonstrated that aside from its effects on food intake, glucose homeostasis, pancreas function, and cardiovascular function, GHSR1a also plays a critical role in the regulation of immune cell function $(13,14)$. Activation of GHS-R1a by ghrelin results in enhanced proliferation and reduced apoptosis of $\mathrm{CD}^{+} \mathrm{T}$ cells, reduced frequencies of Treg cells, and decreased expression of inhibitory co-receptors under sepsis condition (15-17). In lung cancer, GHSR1a has been associated to neuroendocrine differentiation (18). However, the role of GHSR1a in lung cancer microenvironment remains unknown.

The aim of our study is to investigate the role of GHSR1a in $\mathrm{CD}^{+} \mathrm{T}$ cell differentiation and lung cancer progression. We found that GHSR1a deficiency resulted in enhanced Treg cell differentiation but diminished Th17 differentiation in the tumor microenvironment and attenuated anti-tumor immunity. This effect might be attributed to the decreased activation of the mTOR signaling pathway. Our findings shed light on the mechanism of GHSR1a as a master regulator of Th17/Treg balance and anti-tumor immunity in the context of the lung cancer microenvironment.

We present the following article in accordance with the ARRIVE reporting checklist (available at https://dx.doi. org/10.21037/atm-21-5727).

\section{Methods}

\section{T-cell subset isolation}

Lymphocytes were isolated from the spleens of C57BL/6 mice and naive $\mathrm{T}$ cells $\left(\mathrm{CD} 4{ }^{+} \mathrm{CD} 62 \mathrm{~L}^{\text {hi }} \mathrm{CD} 44^{\text {lo }} \mathrm{CD} 25^{-}\right)$were sorted using fluorescence-activated cell sorting (FACS). In brief, after being washed twice with phosphate-buffered saline (PBS) supplemented with $2 \mathrm{mM}$ edetate disodium (EDTA) and $0.5 \%$ Bovine serum albumin (BSA), the cells were re-suspended in the buffer, mixed well with antibodies, and incubated at $4{ }^{\circ} \mathrm{C}$ for 1 hour. After staining, the cells were sorted on a FACStar Plus instrument (Becton Dickinson, USA). The sorting purities were $>95 \%$.

\section{Induction of Th17/Treg differentiation in vitro}

A total of $1 \times 10^{6} \mathrm{CD}^{+} \mathrm{T}$ cells were seeded in 24 well plates containing plate-bound anti-CD $3(1 \mu \mathrm{g} / \mathrm{mL}$, BD Pharmagen, USA) and anti-CD28 $(1 \mu \mathrm{g} / \mathrm{mL}, \mathrm{BD}$ Pharmagen, USA) antibodies, and cultured with $1 \mathrm{~mL}$ RPMI 1640 medium containing 10\% fetal bovine serum (FBS). For the induction of the Th17 cell, the cultures were supplemented with TGF- $\beta$ ( $5 \mathrm{ng} / \mathrm{mL}$, Pepro Tech) and 
IL-6 (20 ng/mL, Pepro Tech) and IL-23 (20 ng/mL, Pepro Tech). For Treg induction, cultures were supplemented with TGF- $\beta$ ( 5 ng/mL, Pepro Tech), and IL-2 (20 ng/mL, Pepro Tech). Four days after induction, the cells were collected. The differentiation of the Th17 cells and Treg cells were examined with flow cytometry assay, quantitative reverse transcription-polymerase chain reaction (qRT-PCR), and enzyme linked immunosorbent assay (ELISA).

\section{Flow cytometry analysis}

For the analysis of the Treg cells, the cells were stained with surface marker $\alpha$ chain of the high-affinity IL-2 receptor (CD25) in PBS containing 1\% BSA and anti-CD25 antibody (eBioscience, USA). Foxp3 staining was then performed in accordance with the manufacturer's instructions (eBioscience, USA). For the analysis of the Th17 cells, the cells were stimulated with leukocyte activation cocktail (BD Pharmagen, USA) for 6 hours, and the cells were then collected and re-suspended in a fixation/ permeabilization solution (BD Pharmagen, USA), and stained with anti-IL-17A antibody (BD Pharmagen, USA).

\section{$R N A$ extraction and real-time $R T-P C R$}

The total RNA of the cells was extracted with TRIzol reagent (Invitrogen, USA) in accordance with the manufacturer's instructions. Complementary DNA (cDNA) was synthesized using a reverse transcriptase kit (Takara, China). The levels of messenger RNA (mRNA) were determined using SYBR Green Real-time PCR master mix (Takara, China) on a 7900HT qRT-PCR machine (Applied Biosystems, USA). The relative mRNA levels were analyzed using the $\Delta \Delta \mathrm{Ct}$ method.

\section{Western blot analysis}

The cells were washed with PBS and lysed in a radioimmunoprecipitation assay lysis buffer with protease and phosphatase inhibitors. Protein concentration was measured using a bicinchoninic acid assay protein assay kit (Tiangen Biotech, China). Proteins were separated with sodium dodecyl sulfate-polyacrylamide gel electrophoresis gels, and transferred onto a polyvinylidene fluoride (PVDF) membrane for immunoblotting. The membranes were blocked in $5 \%$ non-fat milk in Tris-buffered saline (TBS) containing $0.1 \%$ Tween 20 at room temperature for $1 \mathrm{~h}$, and then incubated with primary antibodies at $4{ }^{\circ} \mathrm{C}$ overnight. After washing, the membranes were incubated with horseradish peroxidase (HRP)-conjugated secondary antibody. The Enhanced Chemiluminescence Substrate Kit (Thermo Fisher Scientific, USA) was used for the chemiluminescent detection.

\section{ELISA analysis}

The supernatants of cell cultures were collected. ELISA was performed using a mouse IL-17A and IL-10 quantifying kit (eBioscience, USA) in accordance with the manufacturer's instructions.

\section{Animal studies}

Wild-type (WT) and Ghsr1a/- C57/BL6 mice were obtained from the Shanghai Animal Model Center. Experiments were conducted using female C57/BL6 mice aged 6-8 weeks, weighted $18-20 \mathrm{~g}$. A total of $1 \times 10^{6}$ Lewis lung carcinoma (LLC) cells in $100 \mu \mathrm{L}$ PBS were implanted by subcutaneous injection into the flanks of the Ghsr $1 a^{-1-}$ and WT C57/BL6 mice (5 mice per group). Tumor growth was monitored for 4 weeks. Tumor formation was monitored every other day from day 7 up to 21 days post inoculation. The volumes of tumors were estimated using the following equation: $V=\left(\right.$ length $\times$ width $\left.^{2}\right) / 2$. Tumors were weighed and imaged after surgical removal. The study was approved by the Animal Care Committee of the Shanghai Pulmonary Hospital (No. K19-100Y), in compliance with Shanghai Pulmonary Hospital institutional guidelines for the care and use of animals. A protocol was prepared before the study without registration.

\section{Statistical analyses}

All data are shown as mean \pm standard deviation (SD). The data analyses were performed with the Student's $t$-test or a one-way analysis of variance test. Significant differences were accepted when $\mathrm{P}$ values were $<0.05$. All statistical analyses were calculated and plotted using GraphPad Prism version 7.0 (GraphPad Software, Canada).

\section{Results}

\section{Ablation of GHSR1 a compromised immunity to control tumor growth in the lung cancer mice model}

We first investigated the role of GHSR1a in controlling 
A

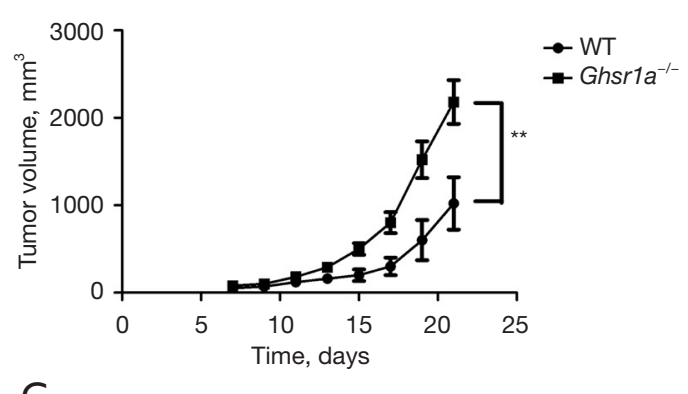

C

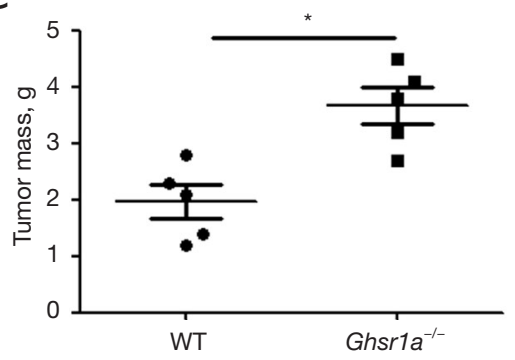

B

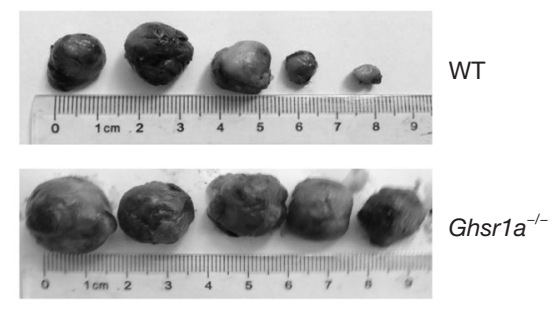

Figure 1 GHSR1a deficiency promoted tumor growth in vivo. Ghsr $1 a^{-/-}$and WT mice were subcutaneously implanted with $1 \times 10^{6}$ LLC cells. Three weeks after the implantation with the LLC cells, the mice were sacrificed, and the tumors were weighed. (A) Time course of tumor growth in the Ghsr $1 a^{-/-}$and WT mice. The values were expressed as mean $\pm \mathrm{SD},{ }^{* *} \mathrm{P}<0.01$. The $\mathrm{X}$-axis (time) denotes days, and the Y-axis (volume) denotes $\mathrm{mm}^{3}$. (B) Images of tumors resected from the mice. (C) Weight of the resected tumors. The values were expressed as mean $\pm \mathrm{SD},{ }^{*} \mathrm{P}<0.05$. GHSR1a, growth hormone secretagogue receptor 1a; WT, wild-type; LLC, Lewis lung carcinoma; SD, standard deviation.

tumor growth using a subcutaneous tumor model. The LLC cells were subcutaneously implanted into the Ghsr $1 a^{-/-}$ mice and WT mice. Four weeks after inoculation, the mice were sacrificed. The tumors in the Gbsr $1 a^{-/-}$mice were larger in size (see Figure 1A,1B) and weight (see Figure 1C) than those of the WT mice, which indicated that GHSR1a deficiency attenuated immunity to control tumor growth.

\section{Ablation of GHSR1a inbibited Th17 differentiation, but promoted Treg cell generation both in vivo and in vitro}

We then analyzed the phenotypes of T cells in draining lymph nodes in the Gbsr $1 a^{-/-}$and WT mice, and found that the proportion of Treg cells was increased while that of Th17 cells decreased in the Ghsr $1 a^{-/-}$mice (see Figure $2 A, 2 B$ ). Thus, the GHSR1a deficiency skewed the TH17/Treg balance toward a Treg bias in the tumor microenvironment.

We further tested the effect of GHSR1a deficiency on the differentiation of Th17 and Treg cells in vitro. IL6 and TGF $\beta$ were added to induce Th17, and IL2 and TGF $\beta$ were added to induce Treg. As Figure $3 A, 3 B$ shows, the
$\mathrm{IL}-17^{+} \mathrm{T}$ cell number was significantly reduced, while the Foxp3+T cell number in Ghsr $1 a^{-/-} \mathrm{CD}^{+} \mathrm{T}$ cells was significantly increased. The ablation of GHSR1a promoted Foxp3 expression and decreased ROR $\gamma \mathrm{t}$ expression (see Figure $3 C$ ). These data demonstrated that GHSR1a deficiency inhibited the differentiation of Th17 cells, but augmented Treg differentiation in vitro.

\section{GHSR1a regulates Th17/Treg balance through mTOR signaling}

Next, we sought to determine the underlying mechanism for the potentiated differentiation of Treg cells and reduced Th17 cells in GHSR-deficient $\mathrm{CD}^{+} \mathrm{T}$ cells. mTOR has been shown to play a critical role in the lineage choices between Th17 and Treg cells (19). Previous studies have shown that GHSR1a regulates the activity of mTOR $(20,21)$. To determine whether mTOR was involved in the loss of balance caused by the deficiency of GHSR1a, the phosphorylation of mTOR was measured using a Western blot. As Figure $4 A$ shows, the phosphorylation of mTOR was decreased in Ghsr $1 a^{-/-} \mathrm{T}$ cells, indicating that the 
A
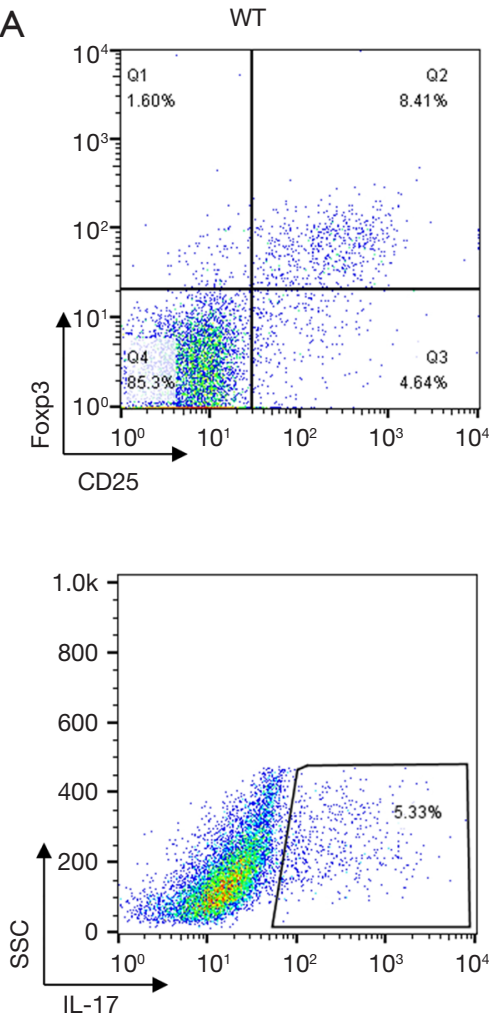

$\mathrm{Ghsr1a}^{-/-}$
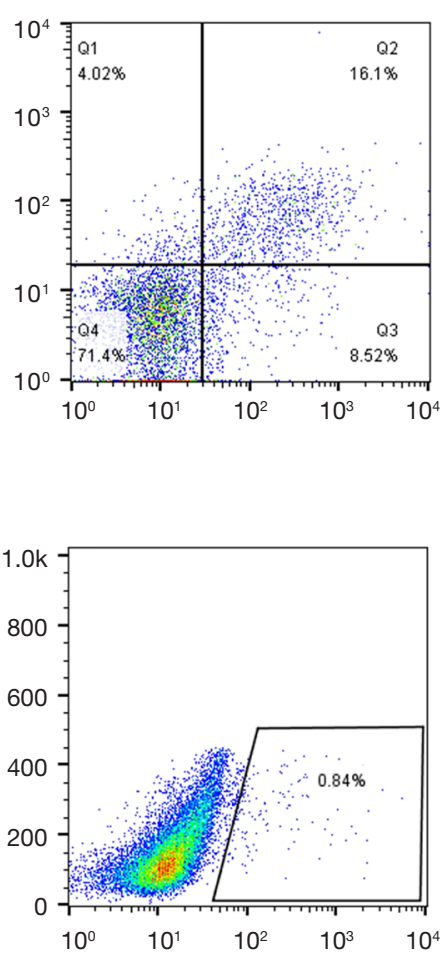

B
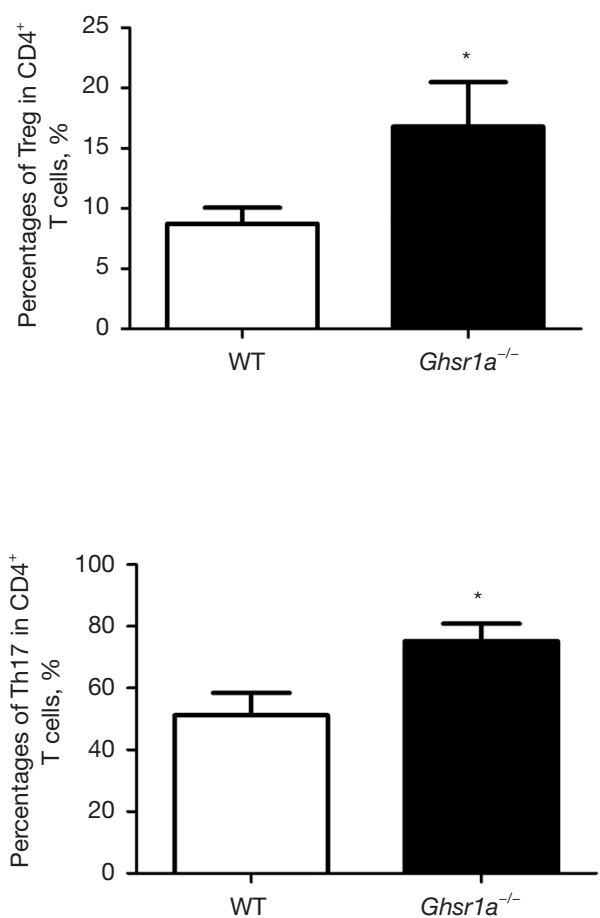

Figure 2 GHSR1a deficiency prohibited the induction of Th17 cells while promoting Treg cells differentiation in the draining of lymph nodes. (A) Representative FACS plots of the percentages of Th17 cells and CD25 $5^{+} \mathrm{Fxp}^{+}{ }^{+}$Treg in $\mathrm{CD} 4^{+} \mathrm{T}$ cells from the draining lymph nodes. (B) A statistical graph of the FACS results. The values were expressed as mean $\pm \mathrm{SD},{ }^{*} \mathrm{P}<0.05$. GHSR1a, growth hormone secretagogue receptor 1a; Th17, T helper 17; FACS, fluorescence-activated cell sorting; CD25, cluster of differentiation 25; Foxp3, forkhead box P3; Treg, regulatory T; SD, standard deviation.

ablation of GHSR might inhibit the differentiation of Th17 cells and promote Treg differentiation through the mTOR signaling pathway. The activation of signal transducer and activator of transcription (STAT) 3 and STAT5 is critical to the differentiation of Th17 and Tregs, respectively $(22,23)$. mTOR has been shown to cross-talk with STAT and play a role in the differentiation of $\mathrm{CD} 4^{+} \mathrm{T}$ cells. Thus, we also examined the phosphorylation of STAT3 and STAT5 in $G_{b s r 1 a^{-/-}}$and WT T cells. As Figure $4 A$ shows, a lower phosphorylation level of STAT3 was observed in Ghsr $1 a^{-/-}$ T cells than WT cells, while the phosphorylation of STAT5 was markedly higher in Ghsr $1 a^{-/-} \mathrm{T}$ cells than WT cells (see Figure $4 A$ ). Thus, GHSR1a might tune the differentiation of Th17/Treg cells through the mTOR signaling pathway and cross-talk with STAT3 and STAT5.

To investigate whether a GHSR1a-regulated Th17/ Treg balance is mTOR-dependent, rapamycin was used to block mTOR signaling, the mRNA expression levels of ROR $\gamma \mathrm{t}$ and IL-17A were examined by qRT-PCR. As Figure $4 B$ shows, ROR $\gamma \mathrm{t}$ mRNA expression was upregulated while Foxp3 was downregulated upon ghrelin stimulation. Conversely, the inhibition of mTOR signaling by rapamycin reversed the effect. These findings suggest that mTOR signaling is dependent on the GHSR1a-mediated regulation of ROR $\gamma \mathrm{t}$ and Foxp3 expression, and contribute to our understanding of how GHSR1a affects the expression of ROR $\gamma \mathrm{t}$ and Foxp3, and thus the balance between Th17 and Treg.

\section{Discussion}

Research has revealed that Th17 and Treg cells play critical roles in the development and progression of lung cancer. It has been established that Treg cells primarily act to dampen immune responses to tumor-antigen; however, the role of Th17 cells in tumor immunity remains controversial. Th17 


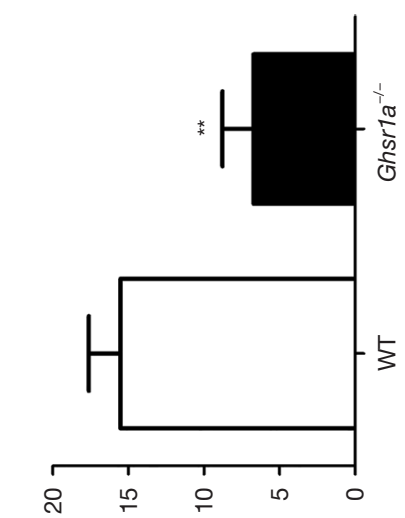

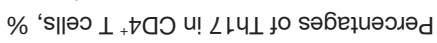

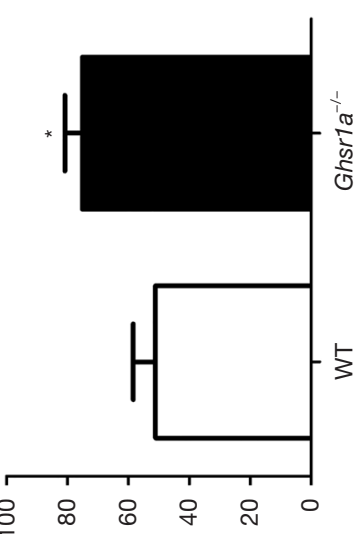

$\%$ 's

$\infty$
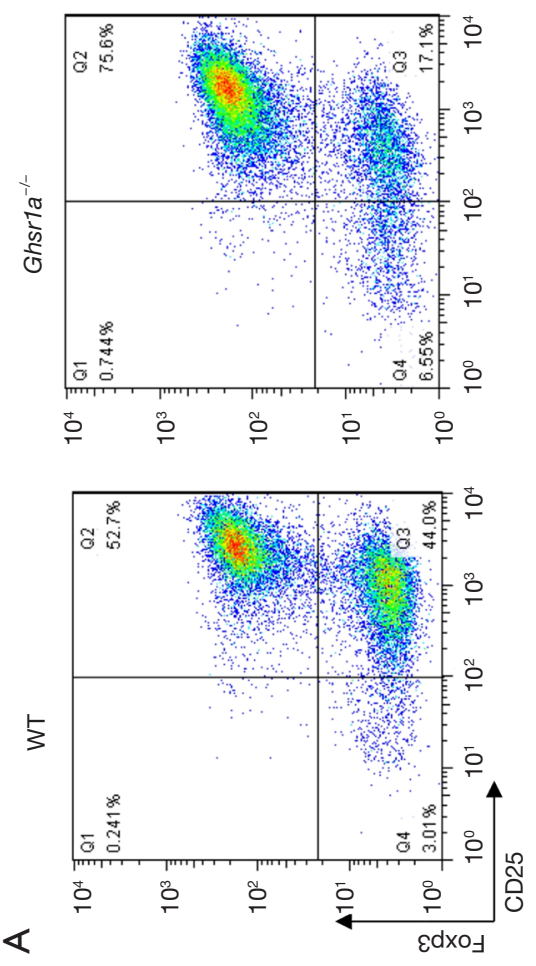

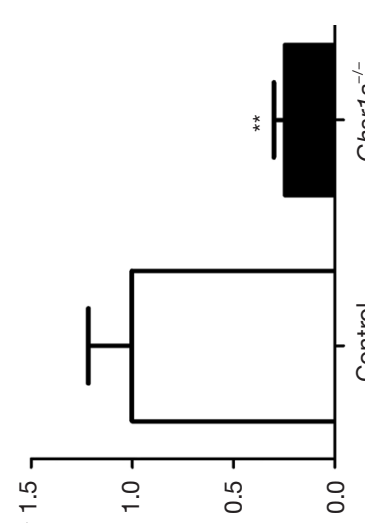

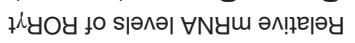

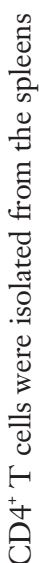

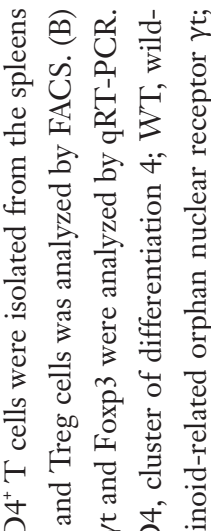

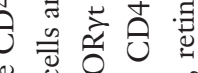

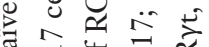

乙

:

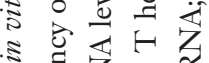

듀워

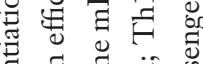

ปี

氙.

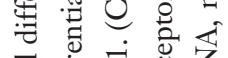

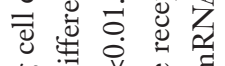

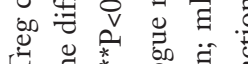

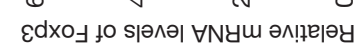
$\cup$
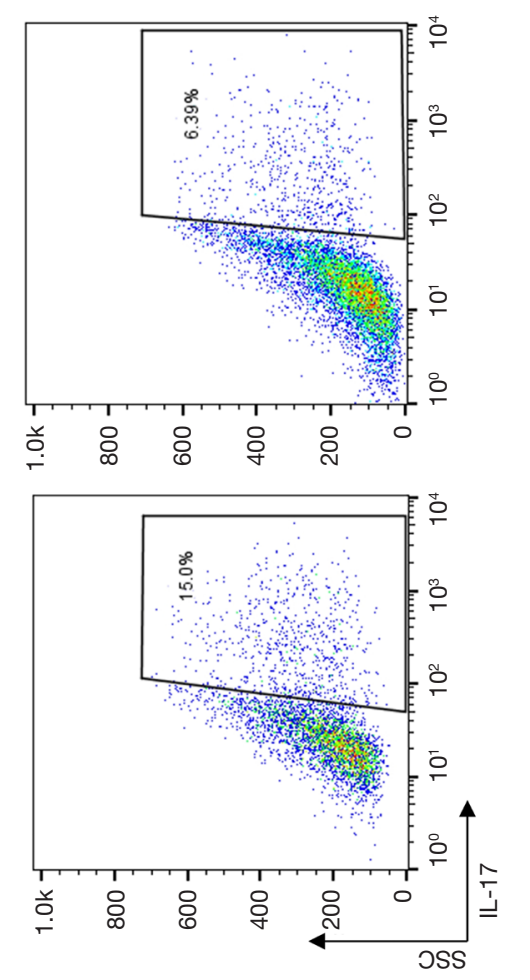
A

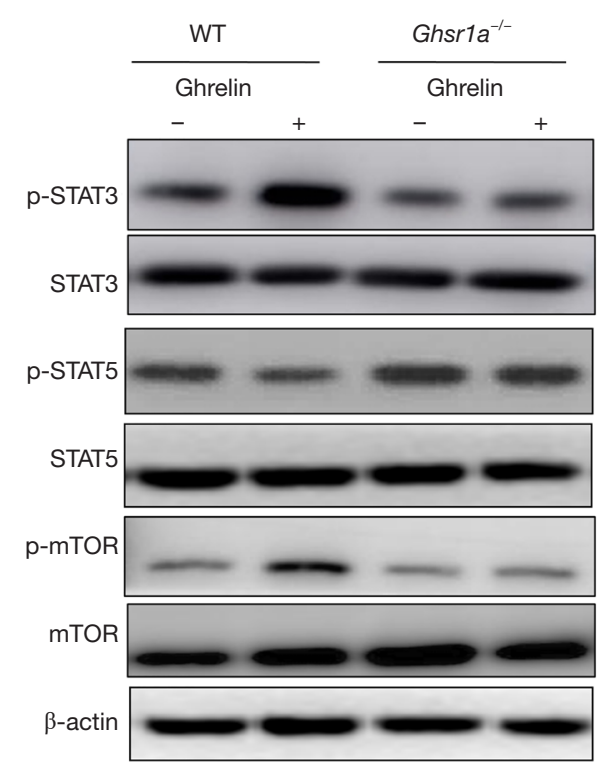

B
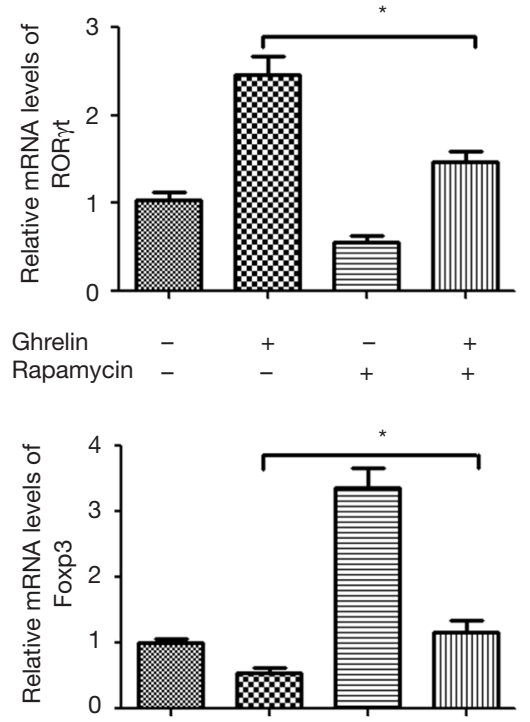

$\begin{array}{lllll}\text { Ghrelin } & - & + & - & + \\ \text { Rapamycin } & - & - & + & +\end{array}$

Figure 4 mTOR cross-talked with the STAT3 and STAT5 signaling pathway to mediate the regulatory effect of GHSR1a on Th17/ Treg balance. (A) Naïve CD4 ${ }^{+} \mathrm{T}$ cells were isolated from spleens of the GHSR1a WT and Gbsr $1 a^{-/-}$mice using FACS, stimulated with $1 \mu \mathrm{g} / \mathrm{mL}$ plate-bound anti-CD3/CD28 and treated with ghrelin and Rapamycin. (A) The phosphorylation of mTOR, STAT3, and STAT5 was analyzed with Western blot. (B) The mRNA levels of ROR $\gamma t$ and Foxp3 were analyzed with qRT-PCR. The values were expressed as mean $\pm \mathrm{SD},{ }^{*} \mathrm{P}<0.05$. mTOR, mammalian target of rapamycin; STAT, signal transducer and activator of transcription; GHSR1a, growth hormone secretagogue receptor 1a; Th17, T helper 17; Treg, regulatory T; CD4, cluster of differentiation 4; WT, wild-type; mRNA, messenger RNA; ROR $\gamma$ t, retinoid-related orphan nuclear receptor $\gamma t$; Foxp3, forkhead box P3; qRT-PCR, quantitative reverse transcription-polymerase chain reaction; SD, standard deviation.

cells induce anti-tumor immunity in some experimental regimens, but actually promote tumor development and progression in others $(24,25)$. Th17 cells display plasticity during differentiation and maintenance. They can originate from Treg cells and also convert into Treg cells (26-28). Additionally, intermediate cells co-expressing ROR $\gamma \mathrm{t}$ and Foxp3 may also arise (29). The imbalance between Th17 and Treg cells may lead to the development and progression of lung cancer. Further, the Th17/Treg ratio has been shown to be negatively correlated with the TNM stages of lung cancer (30-32). Thus, it is of critical importance that novel approaches be developed to restore the Th17/Treg balance to boost an anticancer response.

GHSR is widely expressed in various cell types, including $\mathrm{T}$ lymphocytes (12). The GHSR expression level is significantly upregulated upon $\mathrm{T}$ cell activation, and GHSR can translocate to the lipid raft region of $\mathrm{T}$ cells, activating downstream signaling pathways, and thereby regulating the expression of inflammatory factors (33).
Thus, GHSR appears to play a key role in regulating $\mathrm{T}$ cell function (33). However, the role of GHSR in regulating $\mathrm{T}$ cell differentiation remains unknown. GHSR, which plays an important role in energy homeostasis, has been reported to regulate the activity of mTOR, the sensor of energy status. Given that the bioenergetic demands of Th17 and Treg cells differ (34), some key players in energy metabolism may be a potential target for regulating the immune response and therapeutic interventions for cancer.

In the present study, we demonstrated that the ablation of GHSR1a impaired anti-tumor immunity to control lung cancer growth in vivo. We also found that a deficiency of GHSR1a promotes a shift in the Th17/Treg balance toward enhanced Treg differentiation both in vivo and in vitro, which suggests that GHSR1a plays a key role in regulating $\mathrm{T}$ cell lineage choices between Th17 and Treg cell commitment in the tumor microenvironment. mTOR, which is a central regulator of cellular energy metabolism, has been shown to play a key role in the lineage choices 
between Th17 and Treg cells (19). mTOR inhibition with rapamycin results in the diminished differentiation of Th17 cells but in increase in Treg generation $(35,36)$. We found that GHSR1a deficiency significantly attenuated mTOR phosphorylation, which indicates that GHSR1a plays a role in regulating $\mathrm{mTOR}$ activity during $\mathrm{T}$ cell differentiation. mTOR has been shown to cross-talk with STAT signaling to regulate immune cell fate and function $(37,38)$. STAT3 is a critical transcriptional factor that has been reported to promote Th17 cell differentiation by regulating the expression of ROR $\gamma \mathrm{t}$ and IL-17 production (22). Conversely, STAT5 has been reported to play a prominent role in promoting and maintaining Foxp 3 expression and Treg cell differentiation (39). We showed that GHSR1a regulates Th17/Treg balance by modulating the phosphorylation of mTOR and subsequent phosphorylation of STAT3 and STAT5. GHSR1a positivity modulates the activity of STAT3 and negatively regulates STAT5, and thus affects the reciprocal differentiation of the Treg and Th17 cells via the activation of mTOR signaling.

Interestingly, we observed that GHSR1a had contrasting effects on $\mathrm{CD}^{+} \mathrm{T}$ cell differentiation with ghrelin, which was previously described as being anti-inflammatory and inhibiting the differentiation of Th17 cells (40). Two possibilities could account for this discrepancy. First, other as yet unidentified GHSR1a ligands may exist aside from ghrelin that play a role in $\mathrm{CD}^{+} \mathrm{T}$ cell differentiation. Second, ghrelin/GHSR1a signaling may exert a differential effect on $\mathrm{CD}^{+}{ }^{+} \mathrm{T}$ cell differentiation in different immunological contexts. Further investigations need to be conducted to fully characterize the mechanism of GHSR1a in regulating Th17/Treg balance, and its clinical relevance in lung cancer development and progression.

\section{Conclusions}

In summary, the present study demonstrated that GHSR1a deficiency significantly attenuated anti-tumor immunity in our subcutaneous lung cancer mice model, and revealed the important role of GHSR1a in controlling the delicate balance between Th17 and Treg cells in the tumor microenvironment. We further showed that this effect was dependent on the mTOR signaling pathway. This study advanced our knowledge of the effects of GHSR1a signaling on anti-tumor immunity. Thus, GHSR1a may represent an important target for the development of therapeutic strategies for lung cancer.

\section{Acknowledgments}

The authors appreciate the academic support from AME Lung Cancer Collaborative Group.

Funding: This work was supported by grants from the Shanghai Municipal Health Commission (201840175) and the National Natural Science Foundation of China (81870008).

\section{Footnote}

Reporting Checklist: The authors have completed the ARRIVE reporting checklist. Available at https://dx.doi. org/10.21037/atm-21-5727

Data Sharing Statement: Available at https://dx.doi. org/10.21037/atm-21-5727

Conflicts of Interest: All authors have completed the ICMJE uniform disclosure form (available at https://dx.doi. org/10.21037/atm-21-5727). The authors have no conflicts of interest to declare.

Ethical Statement: The authors are accountable for all aspects of the work, including ensuring that any questions related to the accuracy or integrity of any part of the work have been appropriately investigated and resolved. The study was approved by the Animal Care Committee of the Shanghai Pulmonary Hospital (No. K19-100Y), in compliance with Shanghai Pulmonary Hospital institutional guidelines for the care and use of animals. A protocol was prepared before the study without registration.

Open Access Statement: This is an Open Access article distributed in accordance with the Creative Commons Attribution-NonCommercial-NoDerivs 4.0 International License (CC BY-NC-ND 4.0), which permits the noncommercial replication and distribution of the article with the strict proviso that no changes or edits are made and the original work is properly cited (including links to both the formal publication through the relevant DOI and the license). See: https://creativecommons.org/licenses/by-nc-nd/4.0/.

\section{References}

1. Carbone DP, Gandara DR, Antonia SJ, et al. NonSmall-Cell Lung Cancer: Role of the Immune System 
and Potential for Immunotherapy. J Thorac Oncol 2015;10:974-84.

2. O'Callaghan DS, O'Donnell D, O'Connell F, et al. The role of inflammation in the pathogenesis of non-small cell lung cancer. J Thorac Oncol 2010;5:2024-36.

3. Kim HJ, Cantor H. CD4 T-cell subsets and tumor immunity: the helpful and the not-so-helpful. Cancer Immunol Res 2014;2:91-8.

4. Borst J, Ahrends T, Bąbała N, et al. CD4+ T cell help in cancer immunology and immunotherapy. Nat Rev Immunol 2018;18:635-47.

5. Ganesan AP, Johansson M, Ruffell B, et al. Tumorinfiltrating regulatory $\mathrm{T}$ cells inhibit endogenous cytotoxic $\mathrm{T}$ cell responses to lung adenocarcinoma. J Immunol 2013;191:2009-17.

6. Li Y, Cao ZY, Sun B, et al. Effects of IL-17A on the occurrence of lung adenocarcinoma. Cancer Biol Ther 2011;12:610-6.

7. Afzali B, Lombardi G, Lechler RI, et al. The role of T helper 17 (Th17) and regulatory T cells (Treg) in human organ transplantation and autoimmune disease. Clin Exp Immunol 2007;148:32-46.

8. Bedoya SK, Lam B, Lau K, et al. Th17 cells in immunity and autoimmunity. Clin Dev Immunol 2013;2013:986789.

9. Chen $W$, Jin $W$, Hardegen $\mathrm{N}$, et al. Conversion of peripheral CD4+CD25- naive $\mathrm{T}$ cells to CD4+CD25+ regulatory $\mathrm{T}$ cells by TGF-beta induction of transcription factor Foxp3. J Exp Med 2003;198:1875-86.

10. Zeng H, Chi H. mTOR signaling in the differentiation and function of regulatory and effector T cells. Curr Opin Immunol 2017;46:103-11.

11. Kojima M, Hosoda H, Date Y, et al. Ghrelin is a growthhormone-releasing acylated peptide from stomach. Nature 1999;402:656-60.

12. Gnanapavan S, Kola B, Bustin SA, et al. The tissue distribution of the mRNA of ghrelin and subtypes of its receptor, GHS-R, in humans. J Clin Endocrinol Metab 2002;87:2988.

13. Hattori N. Expression, regulation and biological actions of growth hormone $(\mathrm{GH})$ and ghrelin in the immune system. Growth Horm IGF Res 2009;19:187-97.

14. Smith RG, Jiang H, Sun Y. Developments in ghrelin biology and potential clinical relevance. Trends Endocrinol Metab 2005;16:436-42.

15. Lee JH, Patel K, Tae HJ, et al. Ghrelin augments murine T-cell proliferation by activation of the phosphatidylinositol-3-kinase, extracellular signalregulated kinase and protein kinase $\mathrm{C}$ signaling pathways.
FEBS Lett 2014;588:4708-19.

16. Zhou M, Yang WL, Aziz M, et al. Therapeutic effect of human ghrelin and growth hormone: Attenuation of immunosuppression in septic aged rats. Biochim Biophys Acta Mol Basis Dis 2017;1863:2584-93.

17. Yang WL, Ma G, Zhou M, et al. Combined Administration of Human Ghrelin and Human Growth Hormone Attenuates Organ Injury and Improves Survival in Aged Septic Rats. Mol Med 2016;22:124-35.

18. Herrera-Martínez AD, Gahete MD, Sánchez-Sánchez $\mathrm{R}$, et al. The components of somatostatin and ghrelin systems are altered in neuroendocrine lung carcinoids and associated to clinical-histological features. Lung Cancer 2017;109:128-36.

19. Zhou L, Lopes JE, Chong MM, et al. TGF-beta-induced Foxp 3 inhibits $\mathrm{T}(\mathrm{H}) 17$ cell differentiation by antagonizing RORgammat function. Nature 2008;453:236-40.

20. Delporte C. Structure and physiological actions of ghrelin. Scientifica (Cairo) 2013;2013:518909.

21. Zhang H, Cui Z, Luo G, et al. Ghrelin attenuates intestinal ischemia/reperfusion injury in mice by activating the mTOR signaling pathway. Int J Mol Med 2013;32:851-9.

22. Yang XO, Panopoulos AD, Nurieva R, et al. STAT3 regulates cytokine-mediated generation of inflammatory helper T cells. J Biol Chem 2007;282:9358-63.

23. Saleiro D, Platanias LC. Intersection of $m$ TOR and STAT signaling in immunity. Trends Immunol 2015;36:21-9.

24. Kesselring R, Thiel A, Pries R, et al. Human Th17 cells can be induced through head and neck cancer and have a functional impact on HNSCC development. Br J Cancer 2010;103:1245-54.

25. Zhang JP, Yan J, Xu J, et al. Increased intratumoral IL-17-producing cells correlate with poor survival in hepatocellular carcinoma patients. J Hepatol 2009;50:980-9.

26. Valmori D, Raffin C, Raimbaud I, et al. Human ROR $\gamma t+$ TH17 cells preferentially differentiate from naive FOXP3+Treg in the presence of lineage-specific polarizing factors. Proc Natl Acad Sci U S A 2010;107:19402-7.

27. Koenen HJ, Smeets RL, Vink PM, et al. Human CD25highFoxp3pos regulatory $\mathrm{T}$ cells differentiate into IL-17-producing cells. Blood 2008;112:2340-52.

28. Bailey SR, Nelson MH, Himes RA, et al. Th17 cells in cancer: the ultimate identity crisis. Front Immunol 2014;5:276.

29. Tartar DM, VanMorlan AM, Wan X, et al. FoxP3+RORgammat+ $\mathrm{T}$ helper intermediates display 
suppressive function against autoimmune diabetes. J Immunol 2010;184:3377-85.

30. Hasegawa Y, Takanashi S, Kanehira Y, et al. Transforming growth factor-beta1 level correlates with angiogenesis, tumor progression, and prognosis in patients with nonsmall cell lung carcinoma. Cancer 2001;91:964-71.

31. Jeon HS, Jen J. TGF-beta signaling and the role of inhibitory Smads in non-small cell lung cancer. J Thorac Oncol 2010;5:417-9.

32. Hougaard S, Krarup M, Nørgaard P, et al. High value of the radiobiological parameter Dq correlates to expression of the transforming growth factor beta type II receptor in a panel of small cell lung cancer cell lines. Lung Cancer 1998;20:65-9.

33. Dixit VD, Schaffer EM, Pyle RS, et al. Ghrelin inhibits leptin- and activation-induced proinflammatory cytokine expression by human monocytes and T cells. J Clin Invest 2004;114:57-66.

34. Cluxton D, Petrasca A, Moran B, et al. Differential Regulation of Human Treg and Th17 Cells by Fatty Acid Synthesis and Glycolysis. Front Immunol 2019;10:115.

Cite this article as: $\mathrm{Wu} \mathrm{L}, \mathrm{Li} \mathrm{D}$, Qin L, Wang Q, Saito Y, Sara R, Fan J. Growth hormone secretagogue receptor deficiency promotes lung cancer growth by affecting the Th17/ Treg balance. Ann Transl Med 2021;9(22):1696. doi: 10.21037/ atm-21-5727
35. Li Z, Li Y, Zhang W. Ghrelin receptor in energy homeostasis and obesity pathogenesis. Prog Mol Biol Transl Sci 2013;114:45-87.

36. Woods SC, Seeley RJ, Cota D. Regulation of food intake through hypothalamic signaling networks involving mTOR. Annu Rev Nutr 2008;28:295-311.

37. Zhao Y, Shen X, Na N, et al. mTOR masters monocyte development in bone marrow by decreasing the inhibition of STAT5 on IRF8. Blood 2018;131:1587-99.

38. Chen H, Zhang L, Zhang H, et al. Disruption of TSC1/2 signaling complex reveals a checkpoint governing thymic CD4+ CD25+ Foxp3+ regulatory T-cell development in mice. FASEB J 2013;27:3979-90.

39. Passerini L, Allan SE, Battaglia M, et al. STAT5signaling cytokines regulate the expression of FOXP3 in CD4+CD25+ regulatory T cells and CD4+CD25- effector T cells. Int Immunol 2008;20:421-31.

40. Xu Y, Li Z, Yin Y, et al. Ghrelin inhibits the differentiation of T helper 17 cells through mTOR/STAT3 signaling pathway. PLoS One 2015;10:e0117081. 